\title{
Pattern of patch test reactivity among patients with clinical diagnosis of contact dermatitis: A hospital- based study
}

\author{
Sudip Parajuli', Vikash Paudel ${ }^{2}$, Upama Paudel'1, Dinesh Binod Pokhrel ${ }^{1}$ \\ ${ }^{1}$ Department of Dermatology and Venereology, Maharajgunj Medical Campus, Institute of Medicine, Tribhuvan University, \\ Kathmandu, Nepal, ${ }^{2}$ Department of Dermatology and Venereology, National Medical College, Birgunj, Nepal
}

Corresponding author: Dr. Sudip Parajuli, E-mail: sudipparajuli@gmail.com

\begin{abstract}
Introduction: The patterns of positive patch test in Nepal have not been defined so far. The aim of this study was to describe the patterns of patch test reactivity in suspected Allergic Contact Dermatitis (ACD) patients. Methods: This was a hospital based retrospective study performed to investigate patch test reactivity in patients with ACD from April, 2016 through October, 2016. The data of patients who underwent patch test during this period were extracted and analyzed. Results: A total of 35 patients were included in the study. Nineteen (54.3\%) tested positive to either one or more allergens. Among them, $17(89.4 \%)$ reacted positively to a single allergen. The following patterns of positives were seen: nickel sulfate, 5 (26.3\%), fragrance mix 3 (15.7\%), and parthenium $3(15.7 \%)$. Cobalt sulfate, formaldehyde, potassium dichromate, benzocaine, nitrofurazone, chlorocresol each was positive in single patient. Majority of the patients were housewives $(22.6 \%)$ followed by students and officers (13\% each), farmers (10\%), health care workers (9.7\%), wet work $(6.5 \%)$ and others (20). Less than half (45\%) of the hand eczema showed positive patch test. Similarly, $40 \%$ of the patient of scattered generalized dermatitis showed reactivity to parthenium, nickel sulfate and multiple antigens. Conclusions: The most common allergens identified were nickel sulfate, fragrance mix and parthenium. Since, there is no well defined contact allergen in the Nepalese community, so patch test kits developed elsewhere might not have been beneficial and calls for need of large scale investigation to identify the local allergens.
\end{abstract}

Key words: Allergic contact dermatitis; Nickel sulfate; Patch tests

\section{INTRODUCTION}

Skin diseases are the common and significant cause of morbidity in Nepal. Among them, eczemas are the commonest with high prevalence of allergic contact dermatitis (ACD) [1]. Because of diversity in genetic, environment, topography and occupation of Nepalese population, these factors may also influence the exposure patterns and could be responsible for the variations in the patterns of skin reactivity. Patch test is the gold standard test for allergic contact dermatitis despite the fact that $10 \%$ to $15 \%$ of normal healthy individuals may react to one or more allergens. Over 3000 chemicals are known to cause ACD but, fortunately, only a small number of these chemicals are responsible for symptoms in the majority of cases [2]. The knowledge about the common allergens and a comprehensive history of the patient's exposure will be valuable for selecting the test panels for patch testing. The culprit antigens and the patch test patterns are not defined so far in Nepal. The aim of this study was to describe the patterns of patch test reactivity amongst suspected allergic contact dermatitis in Nepalese population visiting Tribhuvan University Teaching Hospital. 


\section{METHODS}

This was a hospital based retrospective study performed to investigate pattern of patch test reactivity among patients with clinical diagnosis of contact dermatitis in outpatient department at Department of Dermatology and Venereology, Tribhuvan University Teaching Hospital, Kathmandu from April, 2016 through October, 2016. It is a referral hospital for the patients from various parts of Nepal.There were thirty five patients with suspected ACD who underwent patch test with 20 antigens of the Indian Standard series approved by contact and occupational dermatitis forum of India(CODFI) during this period. The test panel consisted of following antigens: Vaseline (as control), Wood alcohol, Peru balsam, formaldehyde, Mercaptobenzothiozole, Potassium bichromate, Nickel Sulfate, Cobalt sulfate, Colophony, Epoxy resin, Paraben mix, Paraphenylene diamine, Parthenium, Neomycin, Benzocaine, Chlorocresol, Fragrance mix, Thiuram mix, Nitrofurazone, and Black rubber mix. The test panel was applied on healthy skin of upper back which was free of lesions that might interfere with the interpretation of the results. The patients were instructed to wear patch for 48 hours and to avoid contact with water, sun exposure and sweating. The results were read after 48 hours, and then again at 72 hours and 96hours after application of patch. The interpretation of the results were done using recommendations of the International Contact Dermatitis Research Group (ICDRG). The demographic and clinical profile along with results of patch tests of all these patients were extracted and filled in preformed pro forma. These data were entered in SPSS-20 software for statistical analysis.

\section{RESULTS}

There were 35 patients with the clinical diagnosis of ACD who underwent patch test during this period. Out of 35 patients suspected to have ACD, $19(54.3 \%)$ individuals tested positive to either one or more allergens; these included 10 males with a mean age of 35.3 years and 9 females with a mean age of 44.6 years. Among the 19 patients, 17 (89.4\%) reacted positively to a single allergen. A female preponderance was evident among the patients with ACD, 20 (57.2\%) females compared to 15 (42.8\%) males, however patch test positivity was more in male than female ( $52 \%$ vs $48 \%$ ).
Majority of the patients were housewives (22.6\%) followed by students and officers (13\% each), farmers $(10 \%)$, health care workers $(9.7 \%)$, wet work $(6.5 \%)$ and others (20).

Among them, 11 (31.4\%) patients presented with hand eczema only where as $7(20 \%)$ had both hand and foot eczema. Other presentations were foot eczema (8.6\%), scattered generalized dermatitis (28.6\%), eczema localized to pubic region $(5.7 \%)$, and eyelid eczema $(5.7 \%)$. Fig. 1 shows the pattern of patch test reactivity among the patients with ACD.

Among the positive results, nickel sulfate (5,26 - 2\%) was found to be the most frequently reacting allergen. Other positive results were seen with fragrance mix $(3,15-7 \%)$ and parthenium (3,15 - 7\%). Cobalt sulphate, formaldehyde, potassium dichromate, benzocaine, nitrofurazone, chlorocresol each was positive in single $(5.2 \%)$ patient. Reactivity against the rest of the panel was not remarkable.

Out of all hand eczema cases, less than half (45\%) showed positive patch test which included fragrance mix (2), chlorocresol (1), nitrofurazone (1) and nickel sulphate (1) whereas foot eczema had reactivity with potassium dichromate only. Similarly, 6(60\%) of the patient of scattered generalized dermatitis did not show reactivity with any of the antigens, comprising positive reaction in each patient only with parthenium, nickel sulphate and multiple antigens.

Twenty three (65.7\%) patients were from the capital city, Kathmandu. History of atopy was present in $17.1 \%$ of the patients.

\section{DISCUSSION}

In Nepal, skin problems are the one of the most common causes of medical consultations with contact dermatitis leading the group. Overall, around half the patients presenting with clinical diagnosis of allergic contact dermatitis tested positive to the patch test allergen. In one of the studies done by Alomgren A et al. [3] , 46.4\% of the patient had tested positive to patch test allergen similar to that seen in our study. This study had addressed the need of development of local allergen for diagnosis of majority of contact dermatitis cases. Nickel sulfate was found to be the most frequently reacting patch test allergen in this study. Similar findings were noted in other studies [4]. Because of the presence of nickel in a large variety 


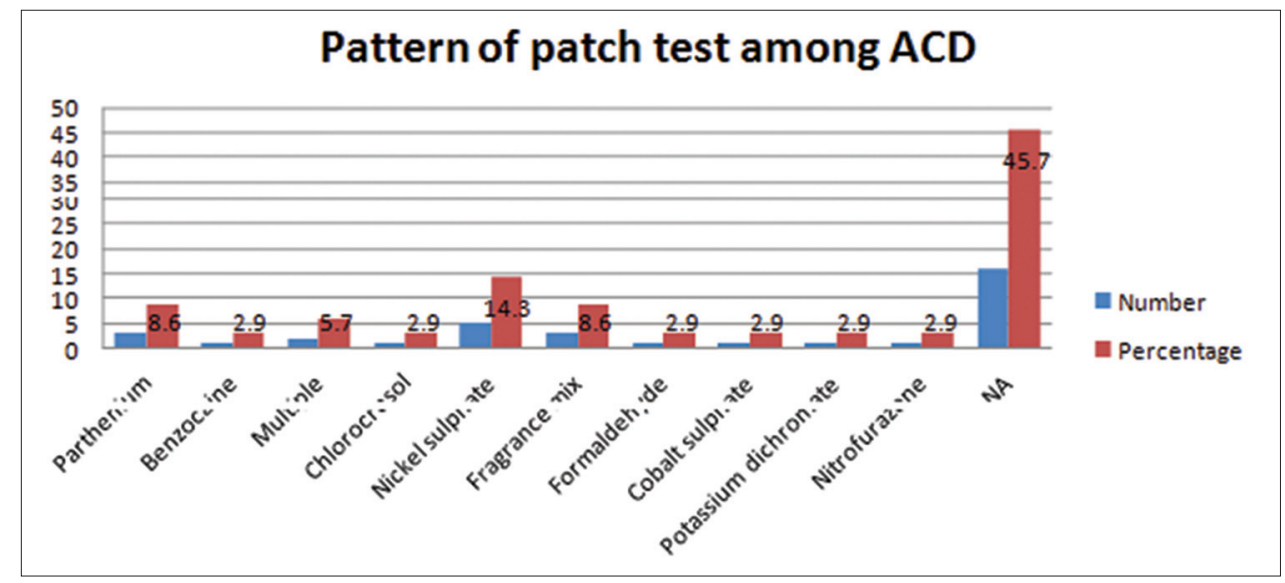

Figure 1: Pattern of patch test among suspected clinical Allergic Contact Dermatitis.

of products it is very difficult to avoid contact with nickel and this is probably the main reason for the high incidence of nickel allergy.

Parthenium and fragrance mix were the second among the most common allergens and majority of patients with scattered generalized dermatitis did not showed positivity with the known antigens. Parthenium hysterophorus has been reported as alien invasive agricultural and environmental problem in Nepal and has been reported since 1967 with rapid expansion in last 20 years [5]. In India, Parthenium hysterophorus has been reported as one of the important cause of airborne contact dermatitis [6]. This further indicates that in future, we might see many more cases of Parthenium dermatitis, as the population gets sensitized to this plant. In addition to Parthenium, Fragrance mix was found to be common allergen which might indicate a majority of our population getting sensitized to cosmetic products containing fragrance mix.

Out of 20 allergens tested in these 35 patients, 12 antigens were found to be negative in all of these cases. This raises a question about the value of the patch test in our context; however, a further large scale study will be needed to validate this observation.

Females were more prone to develop ACD (i.e. 57.1\%) as majority were housewives (20\%) and they were more exposed to household activities, farming, wet works than the males. This female predominance was justified in one of the multicentre studies by Bhattarai $\mathrm{S}$ et al. [7] done in Nepal in patients with hand eczema.

This small scale study gives an overview of contact allergens in different forms of contact dermatitis in our set up. Further studies on patch test with large number of patients done for regional or specific clinical cases of allergic contact dermatitis will be needed in future to define the exact contact allergens in Nepal and their relevance in our local context.

\section{CONCLUSIONS}

Although the patients are exposed to multiple of allergens in day to day life, there is still no well defined contact allergen that causes ACD in our society. Furthermore, the patch test kits developed else-where could not be beneficial in our context as the exposure of the allergen might be different. Although the present study examined a relatively small number of patients, it does however, reveal a pattern of sensitization by contact allergens that this study population was exposed to. The results observed in this small study indicate that there is need for a systematic large scale investigation to identify the local allergens for formulation of policies directed towards avoidance of exposure to the allergens to reduce morbidity.

\section{ACKNOWLEDGEMENTS}

We would like to acknowledge the Department of Dermatology and Venereology, Maharajgunj Medical Campus for providing us the data of patients who underwent patch test during the study period.

\section{REFERENCES}

1. Shrestha DP, Gurung D, Rosdahl I. Prevalence of skin diseases and impact on quality of life in hilly region of Nepal. J Instit Med. 2012:34:44-9.

2. Nelson JL, Mowad CM. Allergic contact Dermatitis: Patch testing Beyond the TRUE Test. J Clin Aesthet Dermatol. 2010;3:36-41.

3. Almogren A, Shakoor Z, GadEI Rab MO, Adam MH. Pattern of patch test reactivity among patients with clinical diagnosis 


\section{www.odermatol.com}

of contact dermatitis: a hospital-based study. Ann Saudi Med. 2012;32:404-7.

4. Liden C. Nickel in jewelry and associated products. Contact Dermatitis. 1992;26:73-5.

5. Shrestha BB, Shabbir A, Adkins SW. Parthenium hysterophus in Nepal: a review of its weed status and possibilities for management. Weed Res. 2015;55:132-44.

6. Handa S, De D, Mahajan R. Airborne contact dermatitis-current perspectives in etiopathogenesis and management. Indian J Dermatol. 2011;56:700-6.
7. Bhattarai S, Rijal A, Agrawal S. Common contact sensitizers among patients with Hand eczema. A multicenter-study in Nepal. NJDVL. 2016;14:14-7.

Copyright by Sudip Parajuli, et al. This is an open-access article distributed under the terms of the Creative Commons Attribution License, which permits unrestricted use, distribution, and reproduction in any medium, provided the original author and source are credited.

Source of Support: Nil, Conflict of Interest: None declared. 